\title{
Where in the World Have All the Strokes Gone?
}

Bart M. Demaerschalk, MD, MSc, FAAN, FRCP(C)

Neurology ${ }^{\circledR}$ 2021;96:1069-1070. doi:10.1212/WNL.0000000000011886

Globally, to date, there have been nearly 125 million confirmed cases of coronavirus disease 2019 (COVID-19) during this pandemic, including >2.7 million deaths, as reported to World Health Organization. Although the common symptoms of COVID-19 are cough, dyspnea, fever, chills, myalgia, anosmia, and ageusia, an increase in several neurologic manifestations, specifically ischemic and hemorrhagic stroke syndromes, has been recognized. Ischemic stroke related to COVID-19 may be secondary to thrombotic microangiopathy, vascular endotheliopathy, arterial dissection, or leukoencephalopathy of the posterior reversible encephalopathy type. ${ }^{1}$ Hemorrhagic stroke associated with COVID-19 may also be due to intracerebral hemorrhage, subarachnoid hemorrhage, or microbleeds. ${ }^{1}$ The incidence of stroke during the pandemic was predicted to increase due to the severe acute respiratory syndrome coronavirus 2 (SARS-CoV-2) virus link to both thrombotic and hemorrhagic risk potential. ${ }^{2}$ Paradoxically, stroke admissions to hospital appeared to decline during the pandemic, speculated to be due to a fear of infection, leading to patients with stroke refusing to call for emergency medical services. ${ }^{2}$ Scientists called for epidemiologic data to characterize and more clearly understand the effect of the COVID-19 pandemic on stroke care. ${ }^{2,3}$

Noguieira et al. ${ }^{4}$ answered the call by conducting a very large cross-sectional, observational, retrospective study across 6 continents, 70 countries, and 457 hospital stroke centers to measure the global impact of the pandemic on overall stroke hospitalizations, administration of IV thrombolysis (IVT), and drip-and-ship transfers related to IVT at the peak of the pandemic compared with 2 similarly long control intervals. The authors reported an $11.5 \%$ decline in stroke admissions, a $13.2 \%$ drop in IVT administration, and an $11.9 \%$ decrease in interfacility transfers for IVT.

The research is not totally novel. Instead, it is confirmatory in that a multitude of regional stroke programs have published this result around the world. ${ }^{5,6}$ However, the Noguieira et al. study is the largest, most comprehensive global retrospective evaluation on the topic of pandemic-associated reduction in stroke phenomenon. The strengths of the study include the inclusion of data from low-income and underresourced countries; evaluation of recovery of stroke hospitalizations in later phases of the pandemic; pragmatic use of existing stroke center databases; case ascertainment verification; prescreening of stroke centers for external confounders that could explain any unexpected changes in volumes; establishment of uniform definitions of what constituted a hospitalization for stroke, IVT, and IVT transfer; and measures to avoid duplicate cases. Potential limitations of the study design include the exclusion of $12 \%$ of eligible stroke centers after screening due to incomplete data or confounders; reliance on participating stroke center data; possible variations in the criteria used for the diagnosis of stroke, description of acute treatment, and documentation of transfer across the various regional and national stroke programs; and the combining of ischemic stroke with TIA and hemorrhagic stroke. The addition or inclusion of telestroke network data may have been helpful to broaden representativeness beyond designated stroke centers. ${ }^{7}$ It may have been interesting to include mechanical thrombectomy as one of the acute treatments investigated for acute ischemic stroke. Although intracerebral hemorrhage was included in the definition of stroke, its potential acute treatments, for example, craniotomy, hematoma evacuation, or decompression, were not evaluated. ${ }^{8}$ The addition of other nonvascular neurologic emergencies and their acute treatments would have offered convenient

\author{
Correspondence \\ Dr. Demaerschalk \\ demaerschalk.bart@ \\ mayo.edu
}

RELATED ARTICLE

Research Article

Global Impact of

COVID-19 on Stroke

Care and Intravenous

Thrombolysis

Page 1074

MORE ONLINE

\section{COVID-19 Resources}

For the latest articles, invited commentaries, and blogs from physicians around the world

NPub.org/COVID19 
comparators. The investigators had the opportunity to specify inclusion of both alteplase and tenecteplase as potential thrombolytics, however did not. Comparing hospitalreported IVT with pharmaceutical company Genentech (Roche Group) national and international reports of thrombolytic dose sales during the same time intervals may have provided an opportunity for validation of results.

Where in the world did all the strokes go? The authors offered many potentially plausible explanations. Their explanations include hospital access related to high COVID-19 burden, although this proved to be unlikely given that the decline has been seen even in centers not overburdened by COVID-19 admissions; patients' fear of contracting the virus; a decline in presentations of TIA and mild stroke; and stay-at-home or shelter-in-place orders and other social distancing measures that may have prevented patients from having their stroke witnessed by others. Like the explanation provided for the witnessed reduction in acute coronary syndromes, another reason for a decline in stroke admissions is a population-level reduction in the consumption of high-sodium fast food, reduction in exposure to air pollution, and improvement in patient behavior. ${ }^{9,10}$ Another possibility offered is the potential reduction in patient exposure to other viruses known to trigger vascular events by masking and social distancing, resulting in reduced stroke incidence.

Beyond explanations offered by the authors, another reason for a reduction in stroke admissions to hospital and IVT is a possible reduction in stroke mimics that are sometimes challenging to distinguish from an acute ischemic stroke syndrome and are often treated with IVT, although unintentionally. Stroke mimics may represent up to a third of all IVT-treated patients and be an important historical baseline source of bias in stroke research. ${ }^{11}$ Any systemic decline in stroke mimics presenting to emergency departments during the COVID-19 pandemic may affect overall stroke syndrome-classified treatments and hospitalizations. Similarly, psychogenic etiologies of stroke-like syndromes, for example, somatic symptom disorders and psychogenic stroke mimics, presenting to emergency departments are plausibly declining as a rise in COVID-19 cases was found to be associated with a decrease in mental health presentations to emergency departments overall. ${ }^{12}$

In summary, Noguieira et al. convincingly demonstrated a global reduction in stroke admissions to hospital, IVT, and interfacility transfers after IVT at the height of the COVID-19 pandemic with a recovery later in the pandemic. Multiple potential systemic explanations were offered, each associated with COVID-19 or related mandates and societal behavior. A true reduction in stroke incidence, although welcomed, is unlikely and cannot be concluded at this point.

\section{Study Funding}

No targeted funding reported.

\section{Disclosure}

The author reports no disclosure. Go to Neurology.org/N for full disclosures.

\section{References}

1. Hernandez-Fernandez F, Sandoval Valencia H, Barbella-Aponte RA, et al. Cerebro vascular disease in patients with COVID-19: neuroimaging, histological and clinical description. Brain. 2020:3089-3103.

2. Lyden PD. Stroke, research and science in the time of COVID. Stroke. 2020;51: 2613-2614.

3. AHA/ASA Stroke Council Leadership. Temporary emergency guidance to US stroke centers during the coronavirus disease 2019 (COVID-19) pandemic. Stroke. 2020;51 1910-1912.

4. Noguieira RG, Qureshi MM, Abdalkader M, et al. Global impact of COVID-19 on stroke care and intravenous thrombolysis. Neurology. 2021;96:e2824-e2838.

5. Jasne AS, Chojecka P, Maran I, et al. Stroke code presentations, interventions, and outcomes before and during the COVID-19 pandemic. Stroke. 2020;51:2664-2673.

6. Sharma M, Lioutas VA, Madsen T, et al. Decline in stroke alerts and hospitalizations during the COVID-19 pandemic. Stroke Vasc Neurol. 2020;5:e000441.

7. Huang JF, Greenway MRF, Nasr DM, et al. Telestroke in the time of COVID-19: the Mayo Clinic experience. Mayo Clin Proc. 2020;95(8):1704-1708.

8. Gonçalves B, Righy C, Kurtz P. Thrombotic and hemorrhagic neurological complications in critically ill COVID-19 patients. Neurocrit Care. 2020;33:587-590.

9. Vlachakis PK, Tentolouris A, Kanakakis I. Concerns for management of STEMI patients in the COVID-19 era: a paradox phenomenon. J Thromb Thrombolysis. 2020; 50:809-813.

10. Park DW, Yang Y. Delay, death, and heterogeneity of primary PCI during the COVID-19 pandemic: an international perspective. J Am Coll Cardiol. 2020;76: 2331-2333.

11. Garg R, Rech MA, Schneck M. Stroke mimics: an important source of bias in acute ischemic stroke research. J Stroke Cerebrovasc Dis. 2019;28:2475-2480.

12. Dragovic M, Pascu V, Hall T, Ingram J, Waters F. Emergency department mental health presentations before and during the COVID-19 outbreak in Western Australia. Australas Psychiatry. 2020;28:627-631. 


\title{
Neurology
}

\author{
Where in the World Have All the Strokes Gone? \\ Bart M. Demaerschalk \\ Neurology 2021;96;1069-1070 Published Online before print March 25, 2021 \\ DOI 10.1212/WNL.0000000000011886
}

This information is current as of March 25, 2021

\begin{tabular}{|c|c|}
\hline $\begin{array}{l}\text { Updated Information \& } \\
\text { Services }\end{array}$ & $\begin{array}{l}\text { including high resolution figures, can be found at: } \\
\text { http://n.neurology.org/content/96/23/1069.full }\end{array}$ \\
\hline References & $\begin{array}{l}\text { This article cites } 11 \text { articles, } 1 \text { of which you can access for free at: } \\
\text { http://n.neurology.org/content/96/23/1069.full\#ref-list-1 }\end{array}$ \\
\hline Citations & $\begin{array}{l}\text { This article has been cited by } 1 \text { HighWire-hosted articles: } \\
\text { http://n.neurology.org/content/96/23/1069.full\#\#otherarticles }\end{array}$ \\
\hline Subspecialty Collections & $\begin{array}{l}\text { This article, along with others on similar topics, appears in the } \\
\text { following collection(s): } \\
\text { All Cerebrovascular disease/Stroke } \\
\text { http://n.neurology.org/cgi/collection/all_cerebrovascular_disease_strok } \\
\text { e } \\
\text { COVID-19 } \\
\text { http://n.neurology.org/cgi/collection/covid_19 }\end{array}$ \\
\hline Permissions \& Licensing & $\begin{array}{l}\text { Information about reproducing this article in parts (figures,tables) or in } \\
\text { its entirety can be found online at: } \\
\text { http://www.neurology.org/about/about_the_journal\#permissions }\end{array}$ \\
\hline Reprints & $\begin{array}{l}\text { Information about ordering reprints can be found online: } \\
\text { http://n.neurology.org/subscribers/advertise }\end{array}$ \\
\hline
\end{tabular}

Neurology ${ }^{\circledR}$ is the official journal of the American Academy of Neurology. Published continuously since 1951, it is now a weekly with 48 issues per year. Copyright @ 2021 American Academy of Neurology. All rights reserved. Print ISSN: 0028-3878. Online ISSN: 1526-632X.

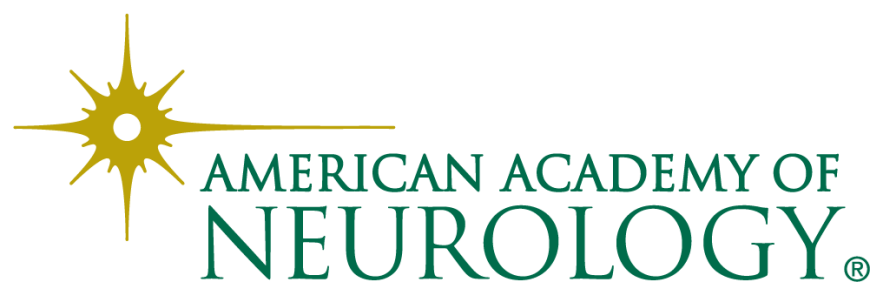

